\title{
Isolated Cecal Necrosis: Report of 2 Cases
}

Nizar Kardoun ${ }^{1}$, Zied Hadrich ${ }^{2}$, Rahma Daoud ${ }^{1}$, Houssem Harbi ${ }^{1}$, Salah Boujelben ${ }^{1}$, and Rafik Mzali ${ }^{1}$

${ }^{1}$ Habib Bourguiba Hospital

${ }^{2}$ University of Sfax Faculty of Medecine of Sfax

May 14, 2021

\begin{abstract}
Isolated cecal necrosis is a rare variant of ischemic colitis which typically simulates the presentation of acute appendicitis. The elderly population is the most affected. We report 2 cases of isolated caecal necrosis, which were preoperatively diagnosed, in 2 female patients with a history of hypertension and renal failure.
\end{abstract}

\section{Hosted file}

Isolated-Cecal-Necrosis-final.pdf available at https://authorea.com/users/412998/articles/ 522058-isolated-cecal-necrosis-report-of-2-cases

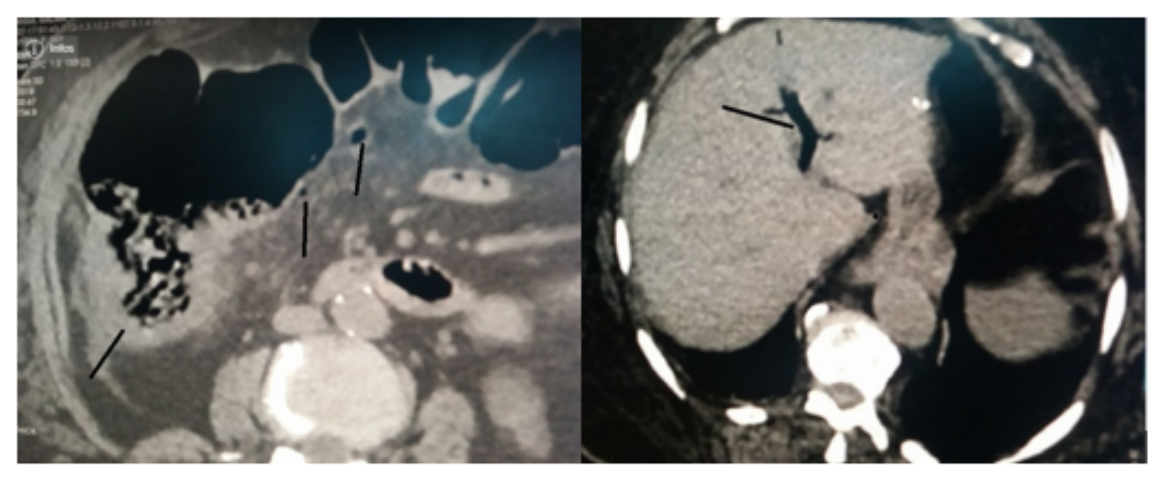



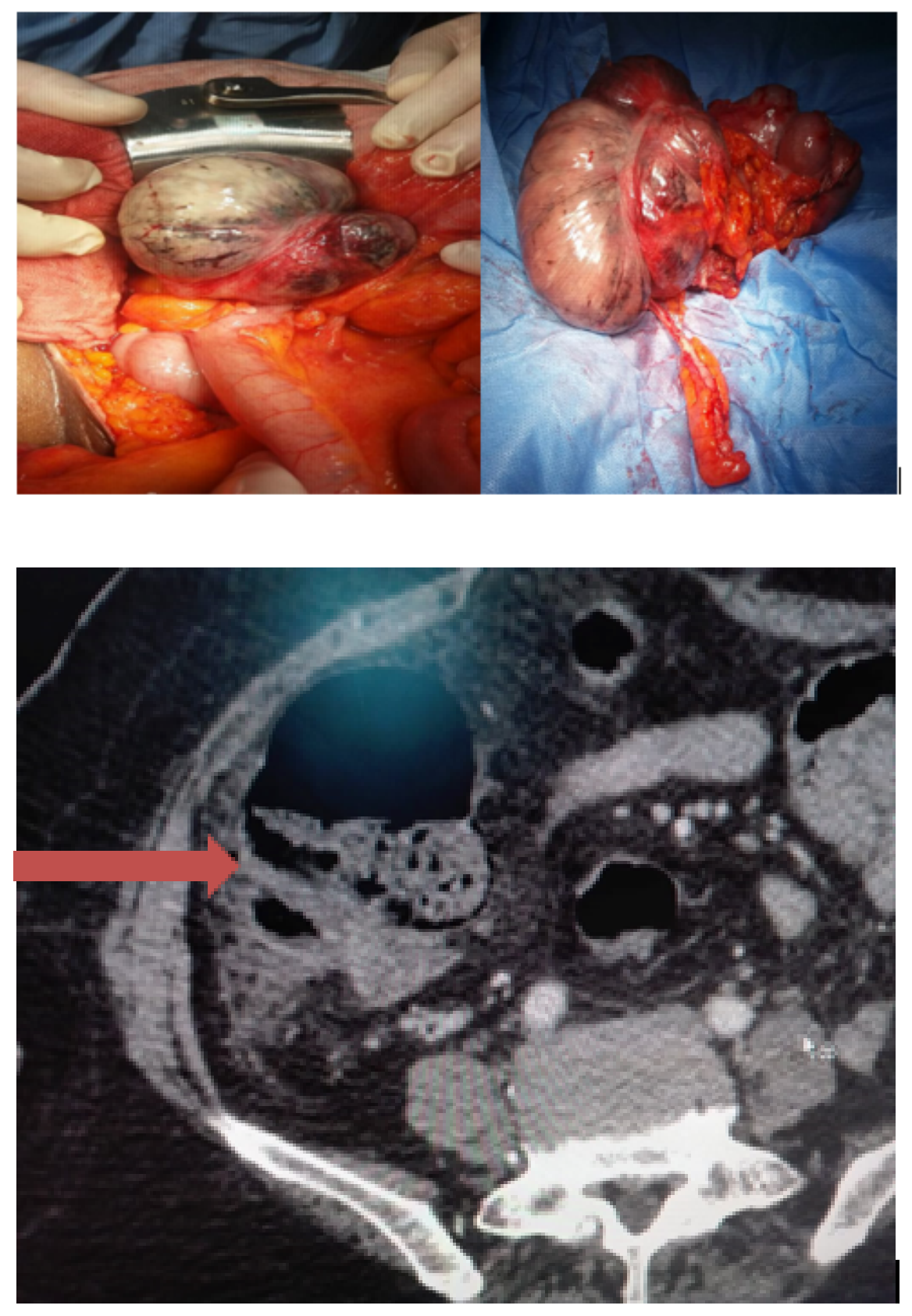


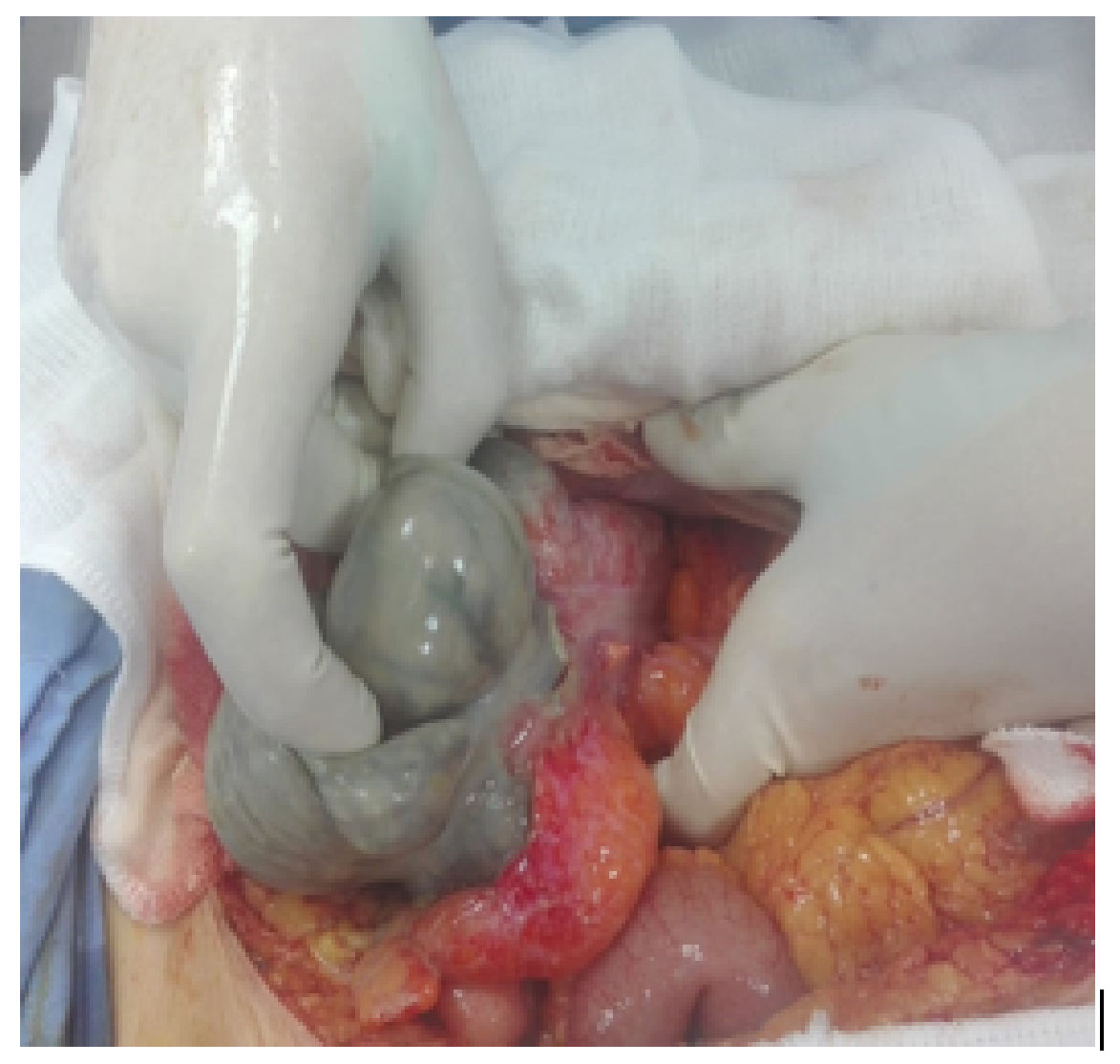

